PontifícIa UNIVERSIDAde CATÓLICA do RIO dE JANEIRO

\title{
A Influência da Liderança Empreendedora sobre o Engajamento e a Rotatividade João Gabriel Coelho Kurrels
}

Trabalho de Conclusão de Curso

CENTRO de CIÊNCIAS SOCIAIS - CCS

DEPARTAMENTO DE ADMINISTRAÇÃo

Graduação em Administração de Empresas 
João Gabriel Coelho Kurrels

\section{A Influência da Liderança Empreendedora sobre o Engajamento e a Rotatividade}

Trabalho de Conclusão de Curso

Trabalho de Conclusão de Curso, apresentado ao programa de graduação em Administração da PUC-Rio como requisito parcial para a obtenção do titulo de graduação em Administração.

Orientadora: Flávia de Souza Costa Neves Cavazotte 
"Educação não transforma o mundo. Educação muda pessoas. Pessoas transformam o mundo" - Paulo Freire 


\section{Agradecimentos}

À minha amada família por todo apoio e incentivo ao longo de minha vida.

À minha namorada, Júlia, pela cumplicidade neste período de grandes transformações.

À Flavia Cavazotte pelas suas aulas e orientação neste trabalho.

Aos professores que tive o prazer de conhecer e que tanto me ensinaram.

Ao Vice-Reitor, Augusto Sampaio, e à Pontifícia Universidade Católica, minha eterna gratidão. 


\section{Resumo}

Em um contexto dinâmico marcado por muitas mudanças tecnológicas, políticas e econômicas, empresas precisam apresentar soluções rápidas para acompanhar estas transformações. Estudos sobre liderança, aspecto central na condução das equipes de trabalho em direção as metas e objetivos, se mostram relevantes. Este estudo tem como objetivo analisar a influência da liderança empreendedora nas empresas da atualidade, investigando seu impacto no engajamento e na rotatividade voluntária dos funcionários, buscando compreender como as pessoas se sentem no ambiente de trabalho e o papel da liderança nesse contexto. Foi feita uma pesquisa quantitativa através de questionários respondidos por 85 profissionais que trabalham em empresas de diversos tipos. Os resultados sugerem que a liderança empreendedora tem impacto positivo no engajamento dos subordinados e negativo na intenção de rotatividade.

\section{Palavras-chave}

Liderança; liderança empreendedora; engajamento no trabalho; rotatividade. 


\section{Abstract}

In a dynamic context, which is characterized by several technological, political and economic changes, companies need to present quick solutions in order to keep up with these changes. Studies on leadership, a central aspect in terms of guiding work teams towards goals and objectives, are, therefore, relevant. This study aims to analyze the influence of entrepreneurial leadership on contemporary companies by investigating its impact on employees' engagement and volunteer turnover in order to understand how people feel in their work environments and the role of leadership in this context. A quantitative survey was applied to 85 professionals that work at different types of companies. The results suggest that entrepreneurial leadership has a positive impact on subordinates' engagement and a negative impact on turnover intent.

\section{Keywords}

Leadership; entrepreneurial leadership; work engagement; turnover. 


\section{Sumário}

1. Introdução 9

2. Referencial teórico 11

$\begin{array}{ll}2.1 \text { Liderança } & 11\end{array}$

2.2 Liderança Empreendedora 13

$\begin{array}{ll}2.3 \text { Engajamento no trabalho } & 15\end{array}$

$\begin{array}{ll}2.4 \text { Rotatividade } & 16\end{array}$

3. Metodologia 19

3.1 Etapas e procedimentos de coleta de dados 19

3.2 Instrumentos de coleta de dados utilizados no estudo 19

$\begin{array}{ll}3.3 \text { Tratamento de dados } & 21\end{array}$

$\begin{array}{ll}3.4 \text { Limitações do método } & 21\end{array}$

4. Apresentação e análise dos resultados 22

4.1 Perfil da amostra 22

4.2 Análise descritiva 22

4.3 Engajamento 24

4.4 Rotatividade $\quad 25$

4.5 Liderança Empreendedora 26

5. Conclusões 29

6. Referências 31 


\section{Lista de ilustrações}

Figura 1 - Hipóteses de pesquisa

Figura 2 - Resultados do estudo

Tabela 1 - Médias, Desvios-Padrão e Correlações

Tabela 2 - Análise de Regressão - Engajamento

Tabela 3 - Análise de Regressão - Intenção de Rotatividade

26

Tabela 4 - Análise de Regressão - Liderança Empreendedora 


\section{Introdução}

O estudo da administração percorre diversas áreas, buscando, principalmente, maior conhecimento sobre o funcionamento das organizações. Nos estudos ao longo do tempo, muitas pesquisas procuraram explorar as diversas estratégias usadas na busca pelo êxito institucional. Sabe-se que para alcançar este êxito, é preciso percorrer por inúmeros fatores que podem apresentar-se como obstáculos ou propulsores de mudanças, como a política, os avanços tecnológicos, a competitividade, entre outros (Peterson \& Hicks, 1995).

Dentre os faotres responsáveis pelo sucesso de uma organização, a maior parte deles pode ser facilmente imitada, como por exemplo os recursos físicos e de infraestrutura ou rede, modelo financeiro ou estratégia competitiva. Para buscar diferenciação nos resultados da organização, Pfeffer(1998) julgava ser necessário investimentos na relação do funcionário com a organização.

Em um mundo extremamente dinâmico e competitivo como o atual, a retenção de colaboradores qualificados torna-se um elemento estratégico para as organizações. Com o avanço da tecnologia, as mudanças ocorrem com maior frequência, portanto, ter uma visão de futuro e oferecer respostas rápidas a essas mudanças pode trazer bons retornos às empresas. Alguns funcionários detêm o conhecimento dos processos de desenvolvimento de novos projetos, o que os torna extremamente valiosos. Perdê-los para empresas concorrentes pode gerar um forte impacto negativo no negócio. Nesse sentido, vale destacar que o engajamento e a retenção desses colaboradores pode ser um elemento chave para o sucesso da empresa.

Os estudos sobre as relações humanas no contexto organizacional ganharam força, principalmente no que tange a liderança, uma vez que é interessante investigar a capacidade de influência dos líderes dentro das organizações, além do seu papel estratégico (Yukl, 2008). Em paralelo, nas economias em desenvolvimento e nos mercados da base da pirâmide em todo o mundo, as atividades empreendedoras vêm crescendo. Para muitos, abrir seu próprio negócio ainda pode ser a única maneira de sustentar sua família (Renko et al., 2015). Essas tendências levaram ao desenvolvimento de estudos sobre liderança empreendedora.

As atitudes dos funcionários dentro das organizações são influenciadas pela visão que eles têm sobre seus gestores no que concerne aos seus valores, crenças e comportamentos. Pesquisas sobre 0 estilo de liderança empreendedora indicam duas características que se destacam, a primeira se 
refere à influência sobre os membros do grupo, para direcioná-los aos objetivos organizacionais que envolvem o reconhecimento, e a segunda trata da exploração de oportunidades empreendedoras (Renko et al., 2015).

Estudos recentes têm pesquisado os efeitos da liderança empreendedora no ambiente de trabalho (Renko, 2018). Ainda assim, existem lacunas na literatura no que diz respeito ao estudo da influência da liderança empreendedora no engajamento dos funcionários e na sua intenção de permanecer ou não na organização. Dessa forma, as questões abordadas neste trabalho visam responder às seguintes perguntas: a liderança empreendedora tem alguma relação com o nível de engajamento de funcionários? Se isso acontece, as pessoas que trabalham com líderes empreendedores demonstram maior engajamento com o trabalho e menor intenção de sair da empresa? Essas questões serão a base das hipóteses de pesquisa discutidas neste trabalho.

O objetivo desta pesquisa é analisar se a liderança empreendedora de supervisores e gestores está associada às atitudes das equipes de trabalho, mais especificamente sua relação com o engajamento dos funcionários e a rotatividade voluntária. Para alcançar este objetivo, foi realizada uma survey baseada em um questionário respondido por uma amostra de 85 profissionais que trabalham em empresas de diversos setores. Os dados foram analisados usando análise de regressão multivariada, através do software SPSS.

As informações que se pretende produzir apresentam contribuição à literatura sobre liderança empreendedora, pois esse estilo de liderança pode vir a aproximar o líder do dia a dia de sua equipe, sendo este uma pessoa entusiasmada e com novas ideias, com a capacidade de influenciar o envolvimento dos funcionários no trabalho. Os resultados podem se mostrar de grande interesse para as empresas no que diz respeito ao critério empreendedor na seleção e desenvolvimento de novos gestores, uma vez que este pode promover maior engajamento individual dos membros da equipe e menores índices de rotatividade, fatores indiretamente relacionados ao desempenho organizacional. 


\section{Referencial teórico}

A referência bibliográfica deste trabalho foi organizada em quatro blocos e tem como objetivo rever as principais teorias acerca dos temas liderança, liderança empreendedora, engajamento e rotatividade. Serão tratadas neste estudo as principais abordagens sobre liderança empreendedora nas organizações, suas características e eficácia, impactos nas atitudes e comportamentos de seus liderados, assim como importantes fatores que influenciam no engajamento individual e na rotatividade voluntária.

\subsection{Liderança}

O tema liderança é muito discutido por diversos autores, no entanto, não há uma única definição do termo que seja consensual. À medida que novos estudos são realizados, alguns conceitos sobre liderança são reforçados e outros acabam criando novas vertentes, com características singulares que as diferenciam umas das outras (Burns, 1978).

A palavra liderar na língua portuguesa possui diferentes significados, tais como comandar, dirigir, conduzir, encabeçar, chefiar. As pesquisas sobre o tema da liderança são compostas por diferentes correntes teóricas, que em alguns momentos divergem, em outros convergem e se complementam (Niemeyer, 2013). Na prática, a liderança é facilmente reconhecida, porém, por conta de sua complexidade, não há uma definição teórica única acerca do tema.

Existem autores que buscam explicar o processo de liderança entre os liderados e seus líderes, lançando luz, também, sobre o processo de percepção dessa relação. Além disso, as pesquisas buscam entender as características e comportamentos dos líderes e como esses conceitos interferem no processo de influência dos liderados (Antonakis \& Day, 2018). Assim dizendo, a liderança é um processo que direciona e guia a organização; ela ocorre em um contexto social, através de um grupo de pessoas que promovem um objetivo, geralmente transformador (Blanco, 2013).

Segundo Kotter (1990), líderes não fazem planos, não resolvem problemas e não organizam pessoas; líderes, na verdade, preparam organizações para mudar. Os líderes procuram mudanças, e, à medida que a mudança se torna 
mais complexa, mais preparado o líder precisa estar. Já os gestores podem se apresentar eficientes em relação à complexidade e à estabilidade que conseguem proporcionar (Kotter, 2001).

$\mathrm{Na}$ tentativa de tornar claras as características da personalidade que diferenciam os líderes dos não líderes, foram concebidos, no início do século XX, estudos sobre a liderança inata, mais especificamente a Teoria dos Traços. Tal abordagem sugere que líderes detentores de determinados traços de personalidade podem ser mais eficazes, visto que isso representa a forma como o líder se comporta em relação à sua equipe. Algumas características do líder, segundo essa teoria, são: autoconfiança, inteligência, sociabilidade, integridade e determinação (Northouse, 2010).

Em seguida, vieram estudos sobre o comportamento do líder em diferentes situações, onde se constatou que os efeitos das circunstâncias afetam a maneira do líder de se portar, sendo conceituada a liderança situacional (Northouse, 2010).

Aos poucos, essa teoria se mostrou uma vertente com diversas limitações, fomentando o surgimento de novos estudos nos quais os aspectos de interação da relação entre líder e seguidores eram considerados, junto com as contingências que influenciam o processo de liderança (Antonakis \& Day, 2018, Northouse, 2010). Diante dessas circunstâncias, as teorias comportamentais surgem com a finalidade de compreender o impacto do comportamento dos líderes através da análise do desempenho efetivo das equipes de trabalho.

Os seguidores e o contexto assumem uma posição de destaque e de maior relevância à medida que diferentes aspectos passam a ser considerados no entendimento do processo de liderança. A partir dos estudos realizados, observa-se que, em virtude da situação e do contexto, deve haver uma adequação no estilo de liderança (Hersey \& Blanchard, 1986, Antonakis \& Day, 2018).

A maneira como uma situação se apresenta ao líder é decisiva para a escolha de qual estilo de liderança seria mais adequado, assim sugerem as teorias de liderança situacional e contingencial. Tendo como conceitos fundamentais o modo de agir do líder frente aos funcionários e aos desafios propostos, utilizando suas vivências e aprendizados ao longo do tempo de maneira assertiva (Stoner \& Freeman, 1995).

Dentre as perspectivas teóricas sobre liderança mais recentes, ou seja, articuladas nas últimas décadas, destacamos, neste trabalho, a liderança empreendedora (Antonakis \& Day, 2018). 


\subsection{Liderança Empreendedora}

Esta seção apresenta uma visão geral sobre a liderança empreendedora e - que ela significa para a prática da liderança. O estilo de liderança empreendedora é definido por Renko et al. (2015) como a capacidade de direcionar e influenciar o desempenho dos membros de uma equipe para atingir objetivos organizacionais que envolvem o reconhecimento e a exploração de oportunidades empreendedoras.

Estudos apontam a liderança empreendedora como um estilo de liderança. Apesar da semelhança com outros estilos de liderança, como liderança transformacional, transacional ou autêntica, a liderança empreendedora nesta linha de pesquisa é considerada um conjunto de comportamentos e atributos de líderes que são distintos o suficiente de outros estilos para garantir o surgimento de uma nova categoria de liderança (Renko et al., 2015).

O diferencial central entre outros estilos de liderança e a liderança empreendedora é o foco do líder em atividades e resultados empreendedores, sendo eles: 1) o reconhecimento e 2) a exploração de oportunidades (Shane \& Venkataraman, 2000). O reconhecimento está relacionado à percepção de uma possibilidade, enquanto a exploração da oportunidade trata-se da obtenção de retornos, através de atividades e investimentos. Dessa forma, a oportunidade empreendedora é a possibilidade de inserir produtos e serviços inovadores em um mercado (Choi \& Shepherd, 2004, Gaglio, 2004, Mueller, 2007).

Para Mainemelis, Kark e Lipitropaki (2015, p. 393), "[o] que torna a liderança empreendedora é determinado pelos objetivos do processo, como em estilos de liderança específicos". Assim, o conceito da liderança empreendedora se dá em dois pilares. O primeiro pilar refere-se a atividades direcionadas a oportunidades e atributos do próprio líder; dentro de contextos organizacionais, os líderes empreendedores, de acordo com pesquisas, são vistos como indivíduos fundamentais que possuem a capacidade de identificar e desenvolver novas oportunidades de negócios (Cunningham \& Lischeron, 1991, Thornberry, 2006). O segundo pilar do conceito de liderança empreendedora se dá no processo de influência, meio pelo qual o líder estimula e motiva seus colaboradores a buscarem o reconhecimento e a exploração de oportunidades, incentivando-os a pensar com ousadia e direcionando sua atenção para visões e metas futuras (Cunningham \& Lischeron, 1991). 
Entre as características dos líderes empreendedores, surgem quatro atributos principais: eles são tomadores de risco, criativos, apaixonados e visionários. Os empreendedores são considerados tomadores de risco quando investem seu tempo, esforço e recursos no desenvolvimento de suas ideias de negócios (Renko et al., 2015). Embora esses riscos não sejam necessariamente tão altos, certamente é verdade a noção de que os empreendedores tendem a ser menos avessos ao risco do que os gerentes corporativos, por exemplo (Stewart \& Roth, 2001).

Outra característica apresentada pelos líderes empreendedores é a criatividade. Essa característica é entendida como a habilidade de se ter ideias assertivas, além da capacidade de se expressar através de pensamentos únicos e investigar novas possibilidades de atuação (Csikszentmihalyi, 1997). No processo de geração de ideias, a criatividade é importante; contudo, nem todas as novas ideias se encaixam como oportunidades empreendedoras. Algumas pesquisas indicam que há uma tendência de liderados usarem mais a criatividade quando recebem apoio dos seus líderes (Tierney, Farmer \& Graen, 1999, Basadur, 2004, Tierney \& Farmer, 2004, Mainemelis, Kark \& Lipitropaki, 2015). Portanto, ao tratar de criatividade como aspecto da liderança empreendedora, entende-se que, apesar do foco estar na criação de resultados que sejam novos e úteis para o público interno ou externo, a ênfase da liderança empreendedora também está na promoção de comportamentos que resultam na invenção e comercialização de produtos, serviços ou processos que, possivelmente, gerarão renda para a organização. A criatividade é uma parte que integra esse processo e, geralmente, os líderes considerados empreendedores são descritos como pessoas criativas (Renko, 2018).

O terceiro atributo que reflete os líderes empreendedores é a paixão. De acordo com Goss (2005), as emoções e os estados afetivos são importantes para os comportamentos empreendedores. Um sentimento forte como a paixão pode ser um impulsionador em relação tanto à tomada de decisão quanto a comportamentos, e é o que os faz persistir diante dos obstáculos (Cardon, Wincent \& Drnovsek, 2009, Chen, Yao \& Kotha, 2009). A paixão de um líder pode influenciar positivamente $o$ afeto dos funcionários no trabalho e a clareza de seus objetivos, afetando, assim, seu compromisso com a organização (Breugst et al., 2012). A paixão também pode facilitar a comunicação da visão de um líder empreendedor para sua organização (Baum \& Locke, 2004).

Por fim, a quarta característica de destaque de um líder empreendedor é a visão. Refletindo uma visão para o futuro, os líderes empreendedores possuem 
um forte desejo de criar, construir ou mudar coisas (Thornberry, 2006). Em suma, a visão como característica da liderança empreendedora é a capacidade de enxergar o futuro da empresa com base no reconhecimento contínuo de novas oportunidades empresariais e buscar a realização dessa visão por meio de ações criativas, inovadoras e, às vezes, arriscadas (Renko et al., 2015).

\subsection{Engajamento no trabalho}

$\mathrm{Na}$ literatura, o conceito de engajamento foi inicialmente proposto por Kahn (1990), segundo o qual pessoas engajadas são aquelas que se envolvem física, cognitiva e emocionalmente com suas atividades de trabalho. A experiência psicológica no trabalho impulsiona as atitudes e os comportamentos das pessoas, sendo que fatores individuais, interpessoais, intergrupais e organizacionais influenciam simultaneamente essas experiências (Kahn, 1990). Ainda de acordo com o autor, que realizou um estudo qualitativo para medir as condições psicológicas de engajamento e desengajamento pessoal no trabalho, foram identificadas três condições psicológicas ligadas ao engajamento e ao desengajamento no trabalho, sendo elas: significado, segurança e disponibilidade. Em outras palavras, os trabalhadores demonstraram maior engajamento em situações que Ihes ofereciam maiores significados e segurança psicológica.

Apesar da correlação entre satisfação no trabalho, envolvimento com a tarefa e comprometimento organizacional, cada conceito tem sua especificidade. Dessa maneira, é válido indicar que o estudo do engajamento no trabalho oferece uma importante contribuição para os saberes organizacionais. Nesse sentido, o engajamento está relacionado à maneira como o funcionário realiza sua tarefa, ainda que o mesmo não esteja satisfeito com seu emprego ou comprometido com a organização (Christian, Garza \& Slaughter, 2011).

Ter funcionários engajados é fundamental para uma empresa, uma vez que pessoas engajadas se apresentam com comprometimento, disposição e com força de vontade, se envolvendo em suas funções (MACEY, SCHNEIDER, 2008). O engajamento proporciona que os processos de uma organização sejam resguardados e aprimorados, mesmo que para isso, os funcionários tenham momentos de estresse na realização de suas atividades (Bakker et al., 2008). 
De acordo com Schaufeli, Taris e Van Rhenen (2007), através de atitudes positivas que impactam em saúde e bem-estar, é possível aumentar o engajamento dos funcionários, consequentemente melhorando seu desempenho e reduzindo o absenteísmo e a intenção de rotatividade. Os efeitos do engajamento têm sido investigados não só para o benefício das empresas, mas também dos funcionários. Aspectos como menor rotatividade, crescimento, satisfação do cliente e maior produtividade e lucratividade podem estar relacionados ao engajamento no trabalho (Bakker, Demerouti \& Sanz-Vergel, 2014). Tsourvakas e Yfantidou (2018) ressaltam que, em um mundo em constante mudança, ter funcionários engajados pode ser uma vantagem competitiva.

Ao falar de engajamento, Schaufeli e Bakker (2003) entendem que este conceito se dá a partir de três pilares: O Vigor, a Dedicação e a Absorção e Concentração. O Vigor pode ser entendido pelo alto nível de energia no trabalho, persistência e resiliência diante de situações difíceis. A Dedicação está relacionada à concentração no exercício das funções, entusiasmo e forte participação dentro da organização. Por fim, a Absorção, que é entendida pela imersão em suas atividades, onde os indivíduos sentem prazer na realização de suas atividades, mesmo que desafiadoras.

Este trabalho parte do pressuposto de que o comportamento empreendedor do líder, composto por um estímulo criativo, com visão de futuro, que demonstra paixão pelo seu trabalho e propenso ao risco, favorece um maior envolvimento físico, cognitivo e emocional por parte dos colaboradores. Assim, apresentamos, abaixo, a primeira hipótese do estudo:

H1 - Liderança empreendedora está positivamente associada ao engajamento do funcionário no trabalho.

\subsection{Rotatividade}

Um dos objetivos deste trabalho é investigar se o estilo de liderança que é experimentado por parte da equipe em relação ao seu supervisor é relevante para a rotatividade voluntária, que é quando um funcionário decide deixar a empresa. Em outras palavras, busca-se entender qual a relação entre a 
liderança empreendedora e o desejo de sair da equipe ou deixar a organização. Para isso, serão tratadas algumas teorias acerca do assunto.

Nas teorias sobre rotatividade (ou turnover), é frequentemente mencionado o comprometimento organizacional e a satisfação, que pode ser apontada como um elemento central nesse assunto. Os dois são vistos como pilares da teoria de rotatividade. Além desses, intenções comportamentais, geralmente expressas como intenção de sair ou ficar, são preditores da rotatividade de pessoal (Steel \& Lounsbury, 2009). Ainda de acordo com os autores, quanto maior o tempo que um indivíduo fica em uma organização, mais difícil é para o mesmo sair. Mesmo que haja possibilidades no mercado de trabalho e o indivíduo tenha capacidade para se buscar novas oportunidades, a medida que o tempo passa, existe uma tendência dos laços sócias e comunitários se fortalecerem, assim como os benefícios financeiros tendem a aumentar (Blanco, 2013).

Outro importante fator é a questão da segurança financeira que o indivíduo possui, pois quanto maior a dependência financeira do trabalho atual, menores as chances de sair sem um novo trabalho em vista. Se o indivíduo possui alguma fonte alternativa de renda que assuma as despesas, então ele possui maior liberdade para cessar uma relação empregatícia, mesmo que não tenha a garantia de outro trabalho (Steel \& Lounsbury, 2009).

Os autores também apontam para a relação da rotatividade com as alternativas de emprego oferecidas no mercado. Segundo essa lógica, antes de deixar o trabalho atual, as pessoas procuram por alternativas levando em consideração os custos que envolvem a decisão de deixar o emprego atual, assim como as recompensas recebidas. Outros fatores, como tamanho da organização, estresse no trabalho e conflitos, também são levados em consideração (Blanco, 2013).

Dessa forma, a liderança empreendedora pode estar diretamente relacionada à rotatividade voluntária, uma vez que esse estilo de liderança apresenta uma visão de futuro do negócio, com paixão pelo faz, sendo criativo e aceitando riscos.

A partir disso, define-se a segunda hipótese do estudo:

H2 - Aa liderança empreendedora está negativamente associada à intenção do funcionário de deixar a empresa.

Os conceitos abordados neste trabalho estão apresentados resumidamente na Figura 1: 


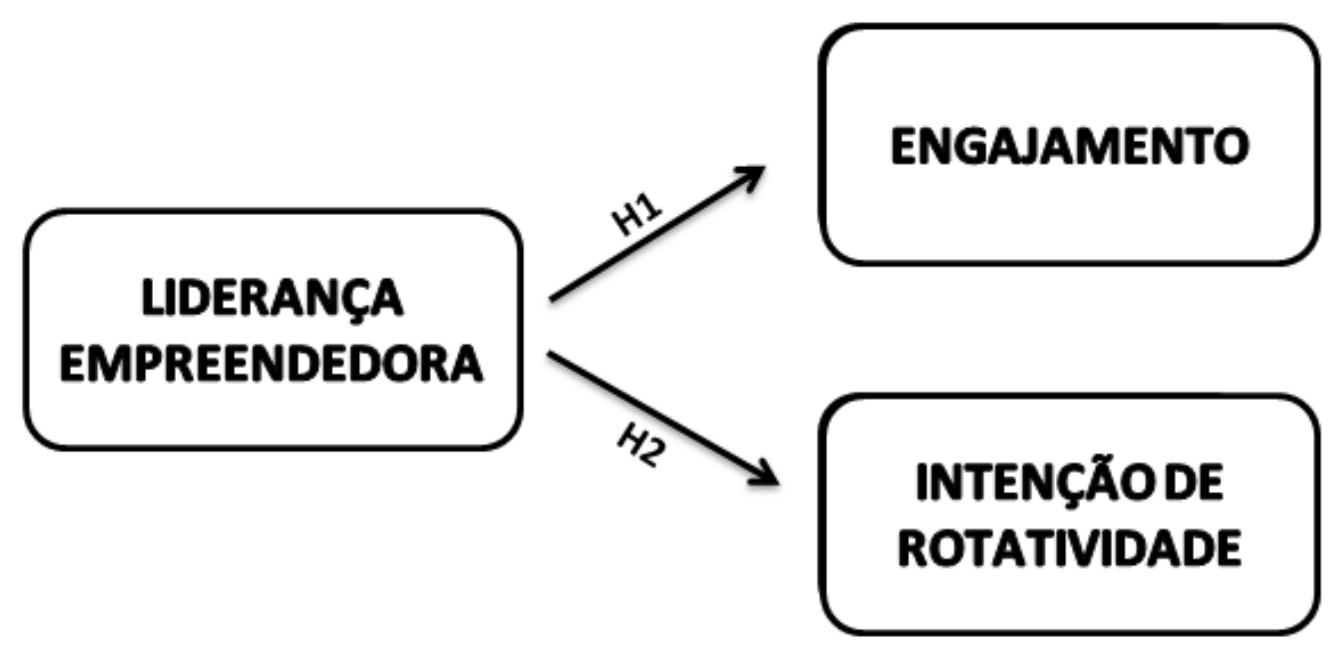

Figura 1 - Hipóteses de pesquisa 


\section{Metodologia}

Este capítulo tem o objetivo de informar sobre os processos metodológicos adotados neste estudo. Está dividido em quatro seções que, respectivamente, informam sobre o procedimento de coleta de dados do estudo, a decisão sobre os instrumentos de medida em cada etapa do processo, o perfil da amostra obtida e as limitações do método.

\subsection{Etapas e procedimentos de coleta de dados}

As hipóteses apresentadas anteriormente foram verificadas nesta pesquisa por meio de dados levantados em uma amostra de conveniência, composta por funcionários de empresas que atuam em diferentes mercados, sendo a maioria pertencente ao setor privado.

Os dados foram levantados durante três semanas por meio de um questionário online. O link de acesso à pesquisa foi enviado por e-mail para potenciais participantes com o convite para participação. Primeiro, foram listadas 200 pessoas que fazem parte da rede de racionamento do autor desta monografia, todos empregados em ambientes corporativos. Desse total, 85 responderam ao questionário de forma completa durante o período estabelecido. Todos os participantes da pesquisa foram informados que suas respostas seriam anônimas, não sendo necessário nenhum tipo de identificação, tratadas com confidencialidade e utilizadas apenas para fins desta pesquisa.

\subsection{Instrumentos de coleta de dados utilizados no estudo}

O questionário utilizado na coleta de dados apresentava aos participantes o contexto geral da pesquisa, seus objetivos e a mecânica de respostas, seguido dos instrumentos de coleta de dados, que incluiu:

\section{i. Questionário de liderança empreendedora desenvolvido por Renko} et al. (2015): O instrumento é composto por oito perguntas associadas a 
aspectos da liderança empreendedora, empregando a escala Likert de cinco pontos, com alternativas variando entre um (nada a ver com meu gestor) e cinco (tudo a ver com meu gestor). São exemplos de itens: "meu gestor tem ideias sobre produtos e serviços completamente novos", "meu gestor aceita riscos" e "meu gestor tem uma visão sobre o futuro do negócio".

ii. Questionário Utrecht Work Engagement (Scale-UWES), sobre engajamento no trabalho, desenvolvido por Schaufeli e Bakker (2003): Composto por nove perguntas, o questionário avalia o sentimento dos participantes em relação ao trabalho, utilizando a escala Likert de sete pontos, com alternativas variando entre zero (nunca ou nenhuma vez) e seis (sempre ou todos os dias). São exemplos de itens dessa escala: "quando me levanto pela manhã, tenho vontade de ir trabalhar" e "fico imerso no meu trabalho".

iii. Questionário de intenção de sair da empresa, composto por três questões, desenvolvido por Mitchell et al. (2001): Seguindo a escala Likert de cinco pontos, esse questionário leva em consideração a vontade dos participantes da pesquisa de trocar de emprego num futuro próximo, e as respostas variam entre um (nada provável) e cinco (muito provável). Um exemplo de item dessa escala é "qual a probabilidade de você deixar a empresa nos próximos 12 meses?".

iv. Variáveis de controle: foram utilizadas como variáveis de controle para esse estudo o perfil sociodemográfico do participante e a sua personalidade. Foram incluídos no questionário oito itens de levantamento sociodemográfico, sendo eles: gênero, idade, grau de escolaridade, tempo de empresa em anos, tipo de empresa, tamanho da empresa, nível hierárquico e sexo do líder direto. Em relação a personalidade, foi aplicado o questionário curto de personalidade dos 5 fatores, desenvolvido por Hahn, Gottschling e Spinath (2012). Esse questionário é composto por dezoito perguntas associadas a seis principais traços de personalidade (abertura, conscienciosidade, extroversão, estabilidade, etc.), adotando a escala Likert de sete pontos, com alternativas variando entre um (não me descreve de maneira nenhuma) e sete (me descreve perfeitamente). São exemplos de itens: "é original, tem novas ideias", "faz as coisas de forma eficaz e eficiente" e "é tranquilo, lida bem com estresse". 


\subsection{Tratamento de dados}

Para realizar as análises do modelo, todas as respostas obtidas através da aplicação do questionário foram transferidas para o Excel, onde foram feitos alguns cálculos para a notação de alguns dados demográficos, como idade e tempo de empresa. Em seguida, os dados foram exportados para o software estatístico SPSS (Statistical Packages for the Social Sciences), onde todas as 85 respostas válidas foram analisadas.

\subsection{Limitações do método}

O método de pesquisa survey verifica associações estatísticas, não sendo possível estabelecer relações de causalidade, já que não é possível controlar nem manipular variáveis como em um experimento. Além disso, a composição da amostra não foi aleatória, e, portanto, os resultados obtidos podem estar associados a características particulares desta amostra, não sendo possível generalizar esse efeito a outros grupos. Vale ressaltar que a pesquisa foi voluntária, ou seja, a amostra foi formada apenas pelas pessoas que se mostraram dispostas a responder ao questionário, o que pode indicar algum tipo de diferenciação desse grupo em relação ao todo. Por fim, todas as perguntas foram objetivas, restringindo o aprofundamento das respostas do participante. 


\section{Apresentação e análise dos resultados}

Este capítulo apresenta, analisa e discute os principais dados e resultados alcançados. Está organizado em seis seções. A primeira expõe e discute o perfil da amostra obtida para a realização do estudo. A segunda trata das correlações entre as variáveis. A terceira, quarta e quinta seção apresentam, respectivamente, as análises de regressão a respeito do engajamento, rotatividade e liderança empreendedora. Por fim, na sexta e última seção, após o tratamento dos dados, os resultados são discutidos.

\subsection{Perfil da amostra}

A amostra aplicada para este estudo contemplou 85 respostas e apresentou equilíbrio em termos de sexo, com $52 \%$ sendo feminino e $48 \%$ masculino. Entretanto, sobre os líderes diretos (supervisores, gerentes, diretores), a maior parte dos líderes é do sexo masculino, com $64 \%$, contra $36 \%$ do sexo feminino. Vale ressaltar que, mesmo com uma participação maior de mulheres na pesquisa, os cargos de liderança ainda apresentam predominância masculina. Sobre a idade dos participantes, a média foi de 32 anos, sendo a mínima 22 e a máxima 66. Já o tempo médio de empresa foi de 4,7 anos, sendo um ano o tempo mínimo e 31 o tempo máximo. Quanto ao grau de instrução, observa-se que $32 \%$ dos respondentes têm algum tipo de pós-graduação (especialização, mestrado ou doutorado), 35\% têm ensino superior completo e $29 \%$ têm ensino superior incompleto. Em relação ao tipo de organização, 92\% dos participantes trabalhavam em instituições privadas e apenas $8 \%$ atuavam no setor público.

\subsection{Análise descritiva}

Nesta análise, foi utilizado o software estatístico SPSS para a realização dos cálculos e análise dos dados. Com o objetivo de traçar o perfil da amostra 
estudada, foi realizada uma análise descritiva das variáveis, onde foi possível calcular as médias, os desvios-padrão, as correlações.

\begin{tabular}{|c|c|c|c|c|c|c|c|c|c|c|c|c|c|c|c|c|c|c|c|}
\hline & Média & $\begin{array}{l}\text { Desvio } \\
\text { Padrã } \\
\end{array}$ & 1 & 2 & 3 & 4 & 5 & 6 & 7 & 8 & 9 & 10 & 11 & 12 & 13 & 14 & 15 & 16 & 17 \\
\hline 1 Gênero & 1,53 & 0,50 & & & & & & & & & & & & & & & & & \\
\hline 2 Idade & 32,06 & 10,24 & $-0,18$ & & & & & & & & & & & & & & & & \\
\hline 3 Escolaridade & 4,07 & 1,00 & $-0,03$ &, $384^{--}$ & & & & & & & & & & & & & & & \\
\hline 4 Anos de empresa & 4,75 & 7,16 & 0,03 &, $670^{-*}$ & 0,06 & & & & & & & & & & & & & & \\
\hline 5 Tipo de empresa & 1,93 & 0,26 & 0,11 &,$- 436^{*}$ & $-0,03$ &,$- 338^{*}$ & & & & & & & & & & & & & \\
\hline 6 Tam. da empresa & 3,20 & 0,94 & 0,13 &, $263^{\circ}$ & 0,02 &, $345^{*}$ &,$- 237^{\circ}$ & & & & & & & & & & & & \\
\hline 7 Nivel hierárquico & 1,59 & 0,95 & $-0,21$ & $486^{*}$ &, $343^{*-}$ &, $312^{*}$ & 0,03 & $-0,05$ & & & & & & & & & & & \\
\hline 8 Sexo do líder direto & 1,36 & 0,48 &, $518^{*}$ & $-0,03$ & $-0,13$ & $260^{\circ}$ & $-0,08$ & 0,18 & $-0,16$ & & & & & & & & & & \\
\hline 9 Conscienciosidade & 5,55 & 1,04 & $-0,02$ & 0,19 & 0,09 &, $334^{--}$ & $-0,19$ &, $422^{*}$ & 0,15 & $-0,07$ & & & & & & & & & \\
\hline 10 Extroversão & 5,28 & 0,97 & 0,13 & $-0,20$ & $-0,09$ & $-0,17$ & 0,13 & $-0,01$ & $-0,05$ & 0,20 & 0,05 & & & & & & & & \\
\hline 11 Amabilidade & 5,55 & 1,03 & 0,13 & $-0,08$ & $-0,12$ & $-0,09$ & 0,21 & 0,02 & $-0,01$ & 0,06 & 0,11 &, $302^{*-}$ & & & & & & & \\
\hline 12 Abertura & 5,44 & 0,98 & $-0,10$ & 0,03 & $-0,09$ & $-0,02$ & $-0,06$ & 0,05 & $-0,05$ & 0,04 &, $287^{*}$ &, $277^{\circ}$ & 0,17 & & & & & & \\
\hline 13 Estabilidade & 3,39 & 1,01 &,$- 218^{*}$ & 0,10 & 0,04 & 0,05 & $-0,04$ & 0,14 & $-0,02$ & $-0,12$ & 0,05 & $-0,03$ & ,298* & $-0,01$ & & & & & \\
\hline 14 Garra & 5,91 & 0,94 & 0,03 & 0,09 & $-0,05$ &, $223^{\circ}$ & $-0,17$ & 0,11 & 0,12 & $-0,01$ &, $585^{*}$ & 0,13 & $264^{\circ}$ & $417^{-*}$ & 0,11 & & & & \\
\hline 15 Lid. Empreendedora & 3,99 & 0,88 & $-0,06$ & $-0,11$ & 0,02 & $-0,17$ &, $253^{\circ}$ & $-0,08$ & 0,14 & $-0,03$ & 0,11 & 0,17 & 0,07 & 0,08 &,$- 219^{\circ}$ & $312^{-}$ & & & \\
\hline 16 Engajamento & 4,39 & 1,14 & $-0,14$ & 0,10 & 0,16 & 0,07 & 0,16 & 0,07 & 0,12 &,$- 244^{\circ}$ &, $342^{*}$ &, $257^{\circ}$ & $369^{*}$ & $268^{\circ}$ & 0,17 &, $438^{-*}$ & $417^{*}$ & & \\
\hline 17 Rotatividade & 2,40 & 1,27 & 0,14 & $-303^{*}$ & $-0,20$ & $-0,18$ & 0,20 & 0,01 & $-0,20$ & 0,08 & $-0,11$ & $-0,06$ & $-0,17$ & $-0,07$ & $-0,20$ & $-0,14$ &,$- 218^{\circ}$ & $-358^{*}$ & \\
\hline
\end{tabular}

Tabela 1 - Médias, Desvios-Padrão e Correlações

É possível observar, na Tabela 1, que há uma correlação negativa entre liderança empreendedora e tempo de trabalho dos funcionários na empresa, indicando que quanto mais tempo o funcionário trabalha na empresa, menor é a percepção de que seus líderes são empreendedores. Outra correlação significativa que está destacada na tabela 1 é entre tempo de empresa e sexo do líder, ou seja, gestores do sexo masculino tendem a ter mais tempo de empresa do que gestores do sexo feminino.

O gênero do participante e do líder, nesta amostra, também tiveram uma correlação positiva forte, o que significa que as mulheres tendem a estar subordinadas a mulheres e homens subordinados a homens. Além disso, os homens aparecem com mais tempo de empresa e níveis de engajamento maiores. Entretanto, não existem diferenças sistemáticas entre homens e mulheres no perfil empreendedor.

Por fim, houve uma correlação negativa entre engajamento e rotatividade, ou seja, pessoas que estão mais engajadas têm menor intenção de deixar a empresa. Para estimar a confiabilidade das escalas usadas, foram calculados os alphas de crombach para as variáveis de liderança empreendedora $(0,905)$, engajamento $(0,949)$ e rotatividade $(0,946)$. 


\subsection{Engajamento}

A fim de analisar as hipóteses propostas que associam o perfil empreendedor do líder ao maior engajamento dos funcionários, foi feita uma sequência de análises de regressão múltipla hierárquica, considerando como variável dependente a média do engajamento. O primeiro conjunto de variáveis foi composto por fatores demográficos: gênero, idade, grau de escolaridade, tempo de empresa e nível hierárquico. Nesse primeiro grupo, nenhuma dessas variáveis apresentou impacto significativo.

O segundo grupo foi composto por tipo de empresa, tamanho da empresa e sexo do líder direto. Dessas variáveis, o tipo de empresa apresentou um resultado marginalmente significativo $(\beta=0,24 ; t=1,95 ; p$-valor $=0,55)$. Apesar de o efeito ser expressivo, o tamanho da amostra reduz a margem de certeza. $O$ sexo do líder também apresentou um resultado marginal $(\beta=-0,25 ; t$ $=-1,89 ; p$-valor $=0,63)$. Pessoas com líderes do sexo masculino, nesta amostra, estão mais engajadas do que pessoas com líderes do sexo feminino. Por fim, o resultado apresentou que as pessoas do grupo de empresas privadas indicaram maior engajamento em suas funções.

Foram incluídas, no terceiro grupo, as seguintes variáveis de personalidade: abertura, amabilidade, conscienciosidade, estabilidade, extroversão e garra. Nesse conjunto, o resultado foi significativo, com o coeficiente de determinação capaz de explicar $47 \%$ da variável engajamento $\left(R^{2}\right.$ $=0,47 ; p$-valor $<0,01)$. Portanto, dentro dessa amostra, pessoas mais extrovertidas $(\beta=0,22 ; t=2,23 ; p$-valor $=0,29)$, amáveis $(\beta=0,22 ; t=2,12 ; p$ valor $=0,38)$ e com mais garra $(\beta=0,34 ; t=2,70 ; p$-valor $=0,09)$ se dizem mais engajadas no trabalho. Embora este estudo não tenha nenhuma hipótese direta a respeito da personalidade, é possível notar a importância dessas variáveis de controle dentro da pesquisa, pois com elas foi possível considerar o efeito da personalidade na relação com o engajamento, podendo enxergar os dados sem esse viés.

No quarto grupo, foi possível verificar um efeito significativo da liderança empreendedora no nível de engajamento dos funcionários $(\beta=0,35 ; t=3,42 ; p$ valor $=0,001)$. Ou seja, quanto mais empreendedor o líder é sob o olhar dos seus liderados, mais engajados os liderados dizem estar. É possível afirmar com segurança que esse resultado não está relacionado à influência da personalidade de quem está respondendo o questionário, nem com o sexo do 
líder ou o tamanho da empresa. De maneira geral, o que determina o engajamento das pessoas dentro da amostra deste estudo são a liderança e a personalidade.

Desse modo, os resultados permitem confirmar a hipótese sobre os efeitos da liderança empreendedora no engajamento

\begin{tabular}{|c|c|c|c|c|c|c|c|c|}
\hline & \multicolumn{2}{|c|}{ Modelo 1} & \multicolumn{2}{|c|}{ Modelo 2} & \multicolumn{2}{|c|}{ Modelo 3} & \multicolumn{2}{|c|}{ Modelo 4} \\
\hline & \multicolumn{2}{|c|}{ (Demográficos) } & \multicolumn{2}{|c|}{ 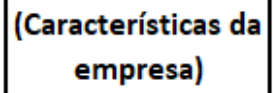 } & \multicolumn{2}{|c|}{ (Personalidade) } & \multicolumn{2}{|c|}{$\begin{array}{c}\text { (Liderança } \\
\text { Empreendedora) }\end{array}$} \\
\hline & Beta & $\mathbf{T}$ & Beta & $\mathbf{T}$ & Beta & $T$ & Beta & $\mathbf{T}$ \\
\hline Gênero & $-0,14$ & $-1,25$ & $-0,06$ & $-0,45$ & $-0,12$ & $-1,02$ & $-0,03$ & $-0,30$ \\
\hline Idade & $-0,08$ & $-0,46$ & 0,01 & 0,03 & 0,07 & 0,45 & 0,01 & 0,08 \\
\hline Grau de escolaridade & 0,16 & 1,29 & 0,13 & 1,01 & 0,20 & 1,88 & 0,20 & $1,99 *$ \\
\hline Anos de empresa & 0,11 & 0,69 & 0,18 & 1,11 & 0,17 & 1,12 & 0,28 & $2,00^{*}$ \\
\hline Nível hierárquico & 0,04 & 0,33 & $-0,03$ & $-0,24$ & $-0,13$ & $-1,17$ & $-0,15$ & $-1,45$ \\
\hline Tipo de empresa & & & 0,24 & $1,95^{*}$ & 0,26 & $2,34^{*}$ & 0,14 & 1,31 \\
\hline Tamanho da empresa & & & 0,12 & 0,98 & 0,05 & 0,48 & 0,02 & 0,24 \\
\hline Sexo do líder direto & & & $-0,25$ & $-1,89$ & $-0,26$ & $-2,23^{*}$ & $-0,32$ & $-2,89 * *$ \\
\hline Conscienciosidade & & & & & 0,04 & 0,27 & 0,05 & 0,41 \\
\hline Extroversão & & & & & 0,22 & $2,23^{*}$ & 0,19 & $2,01^{*}$ \\
\hline Amabilidade & & & & & 0,22 & $2,12^{*}$ & 0,24 & $2,43^{*}$ \\
\hline Abertura & & & & & 0,04 & 0,41 & 0,11 & 1,06 \\
\hline Estabilidade & & & & & $-0,01$ & $-0,12$ & 0,09 & 0,92 \\
\hline Garra & & & & & 0,34 & $2,70^{* *}$ & 0,14 & 1,10 \\
\hline Lid. Empreendedora & & & & & & & 0,35 & $3,42^{* *}$ \\
\hline $\mathbf{R}^{2}$ & 0,0 & & 0,1 & & 0, & & 0, & \\
\hline Delta $\mathbf{R}^{2}$ & & & 0,1 & & 0 & & 0,8 & \\
\hline Delta F & & & 2,86 & & 7,0 & & 11,7 & $D^{* *}$ \\
\hline
\end{tabular}

Nota: $\mathrm{N}=85 \quad{ }^{*} \mathrm{p}<0,05 \quad{ }^{* *} \mathrm{p}<0,01$

Tabela 2 - Análise de Regressão - Engajamento

\subsection{Rotatividade}

Para verificar a hipótese relacionada à intenção de sair da empresa, foi realizada uma série de análises de regressão com as variáveis separadas em blocos. No primeiro, foram considerados fatores demográficos (gênero, idade, grau de escolaridade, tempo de empresa e nível hierárquico). No segundo grupo, foi incluído tipo de empresa, tamanho da empresa e sexo direto do líder. No terceiro grupo, as variáveis de personalidade, e, no quarto, a variável de liderança empreendedora.

Nos três primeiros blocos, nenhuma variável apresentou impacto significativo. Entretanto, ao incluir a variável da liderança empreendedora, 
surgiram efeitos relevantes. O tipo de empresa também teve grande influência na intenção de rotatividade dos funcionários $(\beta=0,31 ; t=2,37 ; p$-valor $=0,21$, uma vez que os participantes da pesquisa que atuam no setor público apresentaram menor intenção de deixar o emprego do que os funcionários do setor privado. Outro resultado que se destacou com um efeito marginal foi a estabilidade emocional $(\beta=-0,23 ; t=-1,94 ; p$-valor $=0,05)$; quanto menor esse fator, maior a tendência em dizer que pretende deixar a empresa. Por último, a variável mais importante, a liderança empreendedora, teve um efeito invertido negativo forte $(\beta=0,41 ; t=-3,26 ; p$-valor $=0,002)$ na intenção de rotatividade, $o$ que significa que, quanto mais empreendedor é o líder, menor a intenção dos seguidores em deixar a empresa.

\begin{tabular}{|c|c|c|c|c|c|c|c|c|}
\hline & \multicolumn{2}{|c|}{ Modelo 1} & \multicolumn{2}{|c|}{ Modelo 2} & \multicolumn{2}{|c|}{ Modelo 3} & \multicolumn{2}{|c|}{ Modelo 4} \\
\hline & \multicolumn{2}{|c|}{ (Demográficos) } & \multicolumn{2}{|c|}{$\begin{array}{c}\text { (Características } \\
\text { da empresa) }\end{array}$} & \multicolumn{2}{|c|}{ (Personalidade) } & \multicolumn{2}{|c|}{$\begin{array}{c}\text { (Liderança } \\
\text { Empreendedora) }\end{array}$} \\
\hline & Beta & $T$ & Beta & $\mathbf{T}$ & Beta & $\mathbf{T}$ & Beta & $\mathbf{T}$ \\
\hline Gênero & 0,09 & 0,82 & 0,06 & 0,46 & 0,06 & 0,40 & $-0,04$ & $-0,32$ \\
\hline Idade & $-0,22$ & $-1,25$ & $-0,16$ & $-0,85$ & $-0,13$ & $-0,63$ & $-0,06$ & $-0,29$ \\
\hline Grau de escolaridade & $-0,10$ & $-0,83$ & $-0,11$ & $-0,90$ & $-0,15$ & $-1,16$ & $-0,15$ & $-1,21$ \\
\hline Anos de empresa & $-0,02$ & $-0,14$ & $-0,05$ & $-0,29$ & $-0,10$ & $-0,54$ & $-0,24$ & $-1,36$ \\
\hline Nível hierárquico & $-0,03$ & $-0,24$ & $-0,05$ & $-0,34$ & $-0,04$ & $-0,27$ & $-0,01$ & $-0,10$ \\
\hline Tipo de empresa & & & 0,12 & 0,97 & 0,18 & 1,33 & 0,31 & $2,37^{*}$ \\
\hline Tamanho da empresa & & & 0,09 & 0,75 & 0,14 & 1,02 & 0,17 & 1,35 \\
\hline Sexo do líder direto & & & 0,03 & 0,20 & 0,05 & 0,37 & 0,12 & 0,88 \\
\hline Conscienciosidade & & & & & $-0,02$ & $-0,10$ & $-0,03$ & $-0,23$ \\
\hline Extroversão & & & & & $-0,10$ & $-0,82$ & $-0,06$ & $-0,52$ \\
\hline Amabilidade & & & & & $-0,20$ & $-1,51$ & $-0,21$ & $-1,76$ \\
\hline Abertura & & & & & $-0,01$ & $-0,07$ & $-0,08$ & $-0,67$ \\
\hline Estabilidade & & & & & $-0,11$ & $-0,93$ & $-0,23$ & $-1,94^{*}$ \\
\hline Garra & & & & & 0,00 & 0,00 & 0,23 & 1,43 \\
\hline Lid. Empreendedora & & & & & & & $-0,41$ & $-3,26 * *$ \\
\hline$R^{2}$ & 0,10 & & 0,13 & & 0,21 & & 0,3 & \\
\hline Delta $R^{2}$ & & & 0,30 & & 0,80 & & 0,1 & \\
\hline Delta F & & & 0,47 & & 1,22 & & 10,65 & ;** \\
\hline
\end{tabular}

Nota: $\mathrm{N}=85 \quad * \mathrm{p}<0,05 \quad * * \mathrm{p}<0,01$

Tabela 3 - Análise de Regressão - Intenção de Rotatividade

\subsection{Liderança Empreendedora}

Buscando entender o que determina a liderança empreendedora na amostra desta monografia, foi feita uma sequência de análises de regressão 
múltipla seguindo os mesmos padrões anteriores, agora com três blocos: variáveis demográficas, características da empresa e traços de personalidade.

Começando pelas variáveis demográficas, ficou evidente que o gênero do líder não tem influência sobre a liderança empreendedora. Entretanto, as mulheres desta amostra tendem a perceber seus superiores como mais empreendedores do que os homens, de maneira geral $(\beta=-0,24 ; t=-1,93$; $p$ valor $=0,57$ ) .

Em relação às características da empresa, é possível destacar que, dentro da amostra deste estudo, o setor privado tem mais líderes empreendedores do que o setor público $(\beta=0,33 ; t=2,76 ; p$-valor $=0,007)$, e que, quanto mais tempo de empresa, menor é a liderança empreendedora que relatada em relação ao líder ( $\beta=-0,34 ; t=-2,10 ; p$-valor $=0,039)$.

Para as variáveis de controle de personalidade, alguns resultados apontaram uma relação negativa: quanto maior a estabilidade emocional do participante, mais crítico ele é em relação ao líder, e, portanto, menor é a liderança empreendedora que ele relata sobre seu superior $(\beta=-0,29 ; t=-2,69$; $p$-valor $=0,009)$. No caso da garra, ocorreu o contrário: quanto maior a garra do respondente, mais ele julga o seu líder como sendo empreendedor $(\beta=0,56 ; t=$ 4,09; $p$-valor < 0,001).

De forma geral, o perfil empreendedor do líder foi confirmado como sendo uma variável importante neste estudo. 


\begin{tabular}{|c|c|c|c|c|c|c|}
\hline & \multicolumn{2}{|c|}{ Modelo 1} & \multicolumn{2}{|c|}{ Modelo 2} & \multicolumn{2}{|c|}{ Modelo 3} \\
\hline & \multicolumn{2}{|c|}{ (Demográficos) } & \multicolumn{2}{|c|}{$\begin{array}{c}\text { (Características } \\
\text { da empresa) }\end{array}$} & \multicolumn{2}{|c|}{ (Personalidade) } \\
\hline & Beta & $\mathbf{T}$ & Beta & $T$ & Beta & $\mathbf{T}$ \\
\hline Gênero & $-0,02$ & $-0,22$ & $-0,09$ & $-0,69$ & $-0,24$ & $-1,93$ \\
\hline Idade & $-0,13$ & $-0,77$ & $-0,02$ & $-0,09$ & 0,18 & 0,98 \\
\hline Grau de escolaridade & $-0,01$ & $-0,05$ & $-0,02$ & $-0,14$ & 0,01 & 0,05 \\
\hline Anos de empresa & $-0,15$ & $-0,99$ & $-0,19$ & $-1,13$ & $-0,34$ & $-2,10^{*}$ \\
\hline Nível hierárquico & 0,25 & $1,98 *$ & 0,21 & 1,55 & 0,06 & 0,48 \\
\hline Tipo de empresa & & & 0,20 & 1,58 & 0,33 & $2,77^{* *}$ \\
\hline Tamanho da empresa & & & 0,04 & 0,33 & 0,08 & 0,68 \\
\hline Sexo do líder direto & & & 0,10 & 0,75 & 0,17 & 1,29 \\
\hline Conscienciosidade & & & & & $-0,04$ & $-0,30$ \\
\hline Extroversão & & & & & 0,10 & 0,92 \\
\hline Amabilidade & & & & & $-0,04$ & $-0,38$ \\
\hline Abertura & & & & & $-0,18$ & $-1,57$ \\
\hline Estabilidade & & & & & $-0,29$ & $-2,69 * *$ \\
\hline Garra & & & & & 0,56 & $4,09 * *$ \\
\hline $\mathbf{R}^{2}$ & 0,0 & & 0,1 & & 0 , & \\
\hline Delta $\mathbf{R}^{2}$ & & & 0,0 & & 0 , & \\
\hline Delta F & & & 0,9 & & 4,5 & \\
\hline
\end{tabular}

Tabela 4 - Análise de Regressão - Liderança Empreendedora

A Figura 2 sintetiza os resultados observados neste estudo.

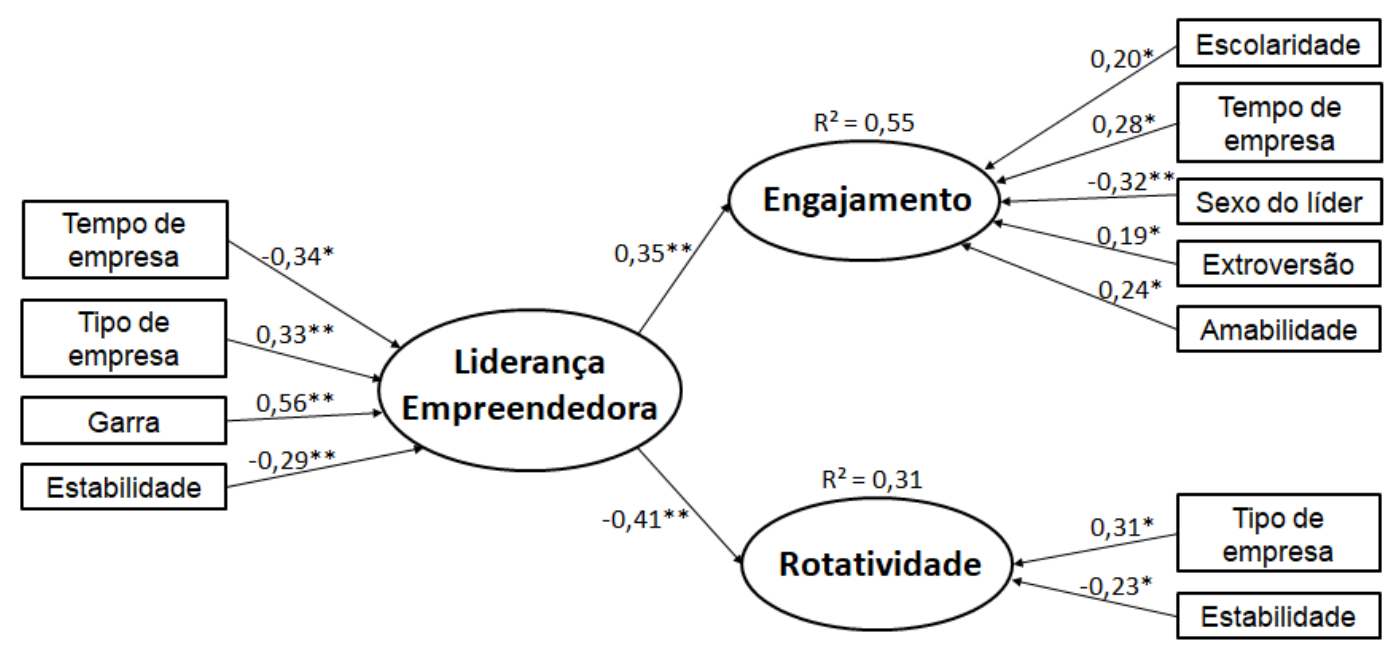

Figura 2 - Resultados do estudo 


\section{Conclusões}

O presente estudo teve como objetivo investigar a influência da liderança empreendedora no engajamento e na rotatividade dos funcionários no âmbito corporativo, buscando compreender como as pessoas se sentem no ambiente de trabalho e o papel da liderança nesse contexto. Os resultados permitem contribuir para um melhor entendimento da importância da liderança empreendedora no cenário brasileiro.

Em um contexto em que as empresas precisam oferecer soluções rápidas para acompanhar as mudanças externas de um mundo cada vez mais dinâmico, a teoria sobre liderança empreendedora ganha destaque. Através desta pesquisa, foi possível levantar informações sobre o impacto que o tipo de liderança, nesse caso a liderança empreendedora, tem sobre a motivação e a intenção de saída dos funcionários, proporcionando, assim, achados que podem servir de apoio para a escolha assertiva do perfil de líderes nas organizações.

Nesse sentido, a primeira constatação relevante é a forte relação entre a liderança empreendedora e o engajamento dos funcionários. Quanto mais tomadores de riscos, criativos, apaixonados e visionários os líderes eram, mais os liderados disseram se envolver com o trabalho. Pessoas engajadas sentem mais satisfação e vigor no trabalho, dedicando-se mais às atividades propostas (Bakker, Demerouti \& Euwema, 2005). Dessa forma, ter líderes empreendedores pode estar associado a um diferencial competitivo da organização.

A relação entre liderança empreendedora e rotatividade também foi confirmada a partir da análise dos dados obtidos através do questionário. Portanto, é possível concluir que os funcionários têm menos intenção de deixar a empresa quando percebem seus líderes como empreendedores.

Além disso, os homens, nesta amostra, apresentaram níveis de engajamento maiores. Uma das razões que pode explicar essa diferença no engajamento é a cultura empresarial, que, sendo mais masculina, pode oferecer maiores dificuldades para mulheres. No entanto, apenas estudos futuros poderão investigar melhor essa observação. Vale destacar que não houve diferença sistemática de estilo de liderança com perfil empreendedor em relação ao gênero.

Quanto às limitações desta pesquisa, o tamanho reduzido da amostra limita o poder estatístico da análise, dificultando a observação de efeitos existentes de menor magnitude. A abrangência de participantes de diferentes 
tipos de empresas e setores é uma limitação, uma vez que outras variáveis relativas a esses contextos e que não estão controladas no estudo podem afetar os resultados obtidos, apesar do tipo de empresa (pública e privada) ter sido considerado. Além disso, a escala de liderança empreendedora ainda é muito recente e ainda não foi completamente validada na língua portuguesa. Mesmo assim, os efeitos achados neste estudo vão ao encontro da literatura já publicada. Ainda, é importante salientar que mais estudos devem ser feitos, podendo, assim, fornecer mais detalhes sobre os impactos que a liderança empreendedora pode causar nas relações e intenções de trabalho, bem como melhor compreender os mecanismos através dos quais líderes empreendedores influenciam as atitudes estudadas.

Sendo assim, para uma pesquisa futura, seria válido aplicar o mesmo questionário em uma única organização, para que haja menos interferência de variáveis que não estejam sendo controladas no estudo. Talvez haja outros impactos mais relevantes da liderança empreendedora, os quais podem ser aprofundados em estudos futuros. 


\section{Referências}

ANTONAKIS, J.; DAY, D. V. The nature of Leadership. 3. ed. Thousand Oaks: SAGE Publications, 2018.

BAKKER, A. B.; DEMEROUTI, E.; EUWEMA, M. Job Resources Buffer the Impact of Job Demands on Burnout. Journal of Occupational Health Psychology, v. 10, p. 170-180, 2005.

BAKKER, A. B.; DEMEROUTI, E.; SANZ-VERGEL, A. Burnout and Work Engagement: The JD-R Approach. Annual Review of Organizational Psychology and Organizational Behavior, v. 1, n. 1, p. 389-411, 2014.

BAKKER, A. B. et al. Work engagement: na emerging concept in occupational heath psycology. Work \& Stress, v. 22, n. 3, p. 187-200, 2008.

BASADUR, M. Leading other to think innovatively together: Creative leadership. Leadership Quarterly, v. 15, p. 103-112, 2004.

BAUM, J. R.; LOCKE, E. The Relationship of Entrepreneurial Traits, Skill, and Motivation to Subsequent Venture Growth. Journal of Applied Psychology, v. 89, p. 587-598, 2004.

BLANCO, I, M. Liderança Autêntica: Suas relações com gênero e os benefícios para a organização. Dissertação (Mestrado em Administração de Empresas) Pontifícia Universidade Católica do Rio de Janeiro, Rio de Janeiro, 2013.

BREUGST, N. et al. Perceptions of Entrepreneurial Passion and Employees' Commitment to Entrepreneurial Ventures. Entrepreneurship Theory and Practice, v. 26, n. 1, 2012.

BURNS, J. M. Leadership. New York: Perenium, 1978.

CARDON, M.; WINCENT, J.; DRNOVSEK, M. The Nature and Experience of Entrepreneurial Passion. The Academy of Management Review, v. 34, p. 511532, 2009.

CHEN, X. P.; YAO, X.; KOTHA, S. Entrepreneur Passion And Preparedness In Business Plan Presentations: A Persuasion Analysis Of Venture Capitalists' Funding Decisions. The Academy of Management Journal, v. 52, n. 1, p. 199214, 2009.

CHOI, Y. R.; SHEPHERD, D. A. Entrepreneurs' Decisions to Exploit Opportunities. Journal of Management, v. 30, p. 377-395, 2004.

CHRISTIAN, M. S.; GARZA, A. S.; SLAUGHTER, J. E. Work engagement: A quantitative review and test of its relations with task and contextual performance. Personnel psychology, v. 64, n. 1, p. 89-136, 2011.

CSIKSZENTMIHALYI, M. Finding Flow: The Psychology of Engagement With Everyday Life. New York: Basic Books, 1997. 
CUNNINGHAM, J.; LISCHERON, J. Defining Entreprenurship. Journal of Small Business Managemen, v. 29, p. 45-62, 1991.

GAGLIO, C. M. The role of mental simulations and counterfactual thinking in the opportunity identification process. Entrepreneurship Theory and Practice, v 28, n. 6 , p. 533-552, 2004.

GOSS, D. Schumpeter's Legacy? Interaction and Emotion in the Sociology of Entrepreneurship. Entrepreneurship Theory and Practice, v. 29, p. 205-218, 2005.

HAHN, E.; GOTTSCHLING, J.; SPINATH, F. M. Short measurements of personality: Validity and reliability of the GSOEP Big Five Inventory (BFI-

S). Journal of Research in Personality, v. 46, n. 3, p. 355-359, 2012.

HERSEY, P.; BLANCHARD, K. H. Psicologia para administradores: a teoria e as técnicas da liderança situacional. São Paulo: EPU, 1986.

KAHN, W. Psychological Conditions of Personal Engagement and Disengagement at Work. The Academy of Management Journal, v. 33, n. 4, p. 692-724, 1990.

KOTTER, J. P. A Force for Change: How Leadership Differs From Management. New York: The Free Press, 1990.

KOTTER, J. P. What leaders really do? Harvard Business Review, v. 97, n. 11, 85-96, 2001.

MACEY, W.; SCHNEIDER, B. The Meaning of Employee Engagement. Industrial and Organizational Psychology, v. 1, p. 3-30, 2008.

MAINEMELIS, C.; KARK, R.; LIPITROPAKI, O. Creative Leadership: A MultiContext Conceptualization. The Academy of Management Annals, v. 9, n. 1, p. 393-482, 2015.

MITCHELL, T. R. et al. Why people stay: Using job embeddedness to predict voluntary turnover. Academy of Management Journal, v. 44, n. 6, p. $1102-$ 1121, 2001.

MUELLER, P. Exploiting entrepreneurial opportunities: the impact of entrepreneurship on growth. Small Business Economics, v. 28, n. 4, p. 335362, 2007.

NIEMEYER, J. R. L. Ética na liderança e LMX (LeaderMember Exchange): uma análise sobre o desempenho individual. Dissertação (Mestrado em Administração de Empresas) - Pontifícia Universidade Católica do Rio de Janeiro, Rio de Janeiro, 2013.

NORTHOUSE, P. G. Leadership: theory and practice. Thousand Oaks: SAGE Publications, 2010.

PETERSON, D. B.; HICKS, M. D. The leader as coach: Strategies for coaching and developing others. Minneapolis: Personnel Decisions, 1995. 
PFEFFER, J. Seven practices of successful organizations. California Management Review, v. 40, n. 2, p. 96-124,1998.

RENKO, M. et al. Understanding and measuring entrepreneurial leadership style. Journal of Small Business Management, v. 53, n. 1, p. 54-74, 2015.

Renko, M. Entrepreneurial leadership. In: ANTONAKIS, J.; DAY, D. (eds.). The nature of leadership. Thousand Oaks: SAGE Publications, 2018. p. 381-407.

SCHAUFELI, W. B.; BAKKER, A. B. Utrecht work engagement scale: Preliminary manual. Utrecht: Occupational Health Psychology Unit of Utrecht University, 2003.

SCHAUFELI, W. B.; TARIS, T. W.; VAN RHENEN, W. Workaholism, burnout and engagement: one of a kind or three different kinds of employee well-being? Applied Psycology: An International Review, v. 57, n. 2, p. 173-203, 2007.

SHANE, S.; VENKATARAMAN, S. The Promise of Entrepreneurship as a Field of Research. The Academy of Management Review, v. 25, n. 1, p. 217-226, 2000.

STEEL, R. P.; LOUNSBURY, J. W. Turnover Process Models: Review and Synthesis of a Conceptual Literature. Human Resource Management Review, 19, 271-282, 2009.

STEWART, W.; ROTH, P. Risk Propensity Differences Between Entrepreneurs and Managers: A Meta-Analytic Review. The Journal of Applied Psychology, v. 86, p. $145-53,2001$.

STONER, J. A. F.; FREEMAN, R. E. Administração. 5 ed. Rio de Janeiro: Prentice Hall do Brasil, 1999.

THORNBERRY, N. Lead like an entrepreneur. New York: McGraw Hill Professional, 2006.

TIERNEY, P.; FARMER, S. M. The Pygmalion Process and Employee Creativity. Journal of Management, v. 30, n. 3, p. 413-432, 2004.

TIERNEY, P.; FARMER, S. M.; GRAEN, G. B. An examination of leadership and employee creativity: The relevance of traits and relationships. Personnel

Psychology, v. 52, p. 591-620, 1999.

TSOURVAKAS, G.; YFANTIDOU, I. Corporate social responsibility influences employee engagement. Social Responsibility Journal, v. 14, n. 1, p. 123-137, 2018.

YUKL, G. How Leaders Influence Organizational Effectiveness. The Leadership Quarterly, v. 19, p. 708-722, 2008. 